\title{
NOVAS IMAGENS PARA MULHERES NEGRAS NÃO LOUCAS
}

Renata Carmo Alves ${ }^{1}$

\begin{abstract}
Resumo
O ensaio propõe pensar as fissuras simbólicas (e psíquicas) do racismo enquanto prática discursiva do pensamento moderno. A (produção da) loucura, portanto, é um signo de deslegitimação imposto e um esquema estratégico de aniquilamento do corpo da mulher negra e de promoção de exclusão. Assim, a construção de novas bases epistemológicas de compreensão social é tanto parte das lutas democráticas atuais quanto uma questão de saúde pública.
\end{abstract}

\section{Palavras-chave}

Mulher negra. Trauma. Loucura. Novas narrativas.

Há uma grande dificuldade em pensar o processo traumático do racismo em nossa sociedade, de uma forma em geral, e em mulheres negras, especificamente. Viver sob o signo da raça atrelado ao marcador de gênero causa profundas dores e este também é um processo de morte. Antes da rápida sugestão de que é possível torcer o significado da raça e entender o corpo feminino negro como lugar de potência (a palavrinha da moda), talvez seja fundamental o questionamento do quanto há de violência na pressa utilitária da afirmativa como um destino único. Isto para não incorrer simplesmente no profundo esvaziamento da questão. No que diz respeito ao processo de significação, entender a dor, atravessar a dor e transmutá-la é um processo que se faz em perlaboração ${ }^{2}$, no entendimento de um destino que foi pensado como trágico. A questão é que, para além das negativas quanto à insistência da raça, ao corpo feminino negro não é permitido o processo de travessia. A sociedade está a todo tempo insistindo na manutenção da escassez e na reiteração do(s) trauma(s) como um processo

${ }^{1}$ Graduada em Artes Cênicas (Unirio), Cinema (Unesa), Jornalismo (Unesa), pós-graduada em Telejornalismo (Unesa), Mestre em Literatura, Cultura e Contemporaneidade (Puc) e Doutoranda em Literatura, Cultura e Contemporaneidade (Puc).

${ }^{2}$ A partir da noção de perlaboração cunhada por Freud em 1914, Lacan desenvolve sua perspectiva de análise na qual o tempo é necessário para que o sujeito formule suas interpretações frente às resistências. Ao desenvolver a teoria do tempo lógico, em que o tempo está associado ao trabalho do simbólico, Lacan pontua três instâncias que a constituem: o instante de ver, o tempo para compreender e o momento de concluir. Entretanto, em Lacan, o tempo da perlaboração, atrelado ao analítico, leva em consideração o momento de concluir, impondo, portanto, limites ao simbólico. O tempo da análise, o difícil trabalho da perlaboração, torna-se parte constituinte de uma outra estrutura temporal, o tempo lógico, que considera os efeitos que possam ser produzidos na clínica psicanalítica a partir da causa do sujeito. 
de reificação. É um processo diário e inesgotável, onde manter-se plenamente viva e saudável é um estado que enfrenta inúmeras camadas de impossibilidades; sendo, portanto, a loucura um fantasma anunciado. Resistir a ela é, em si, um ato de rebeldia.

Existem três significados atrelados ao significante "negra" que são fruto dos processos coloniais abissais que marcam não apenas o modus operandi do brasileiro, mas o pensamento comum de uma sociedade que se funda sob o paradigma da “apropriação/violência" (SANTOS, 2007): a mulher negra louca, a mulher negra raivosa e a mulher negra hiper sexualizada - tema sobre os quais há uma vasta bibliografia, já debatida por diversos autores ${ }^{3}$. Quanto à loucura enquanto processo social, ela existe no imbricamento dos outros dois (mas não apenas) e todos incididos no paradigma da deriva e da vulnerabilidade. Com insistência somos chamadas de loucas. Com perversidade somos chamadas de raivosas e o conteúdo que produzimos de "agressivo". A pergunta é: “agressivo para quem, cara pálida?" Nossos corpos são incessantemente sexualizados. Estamos a todo tempo em desamparo. Somos impedidas. Nossa ascensão, quando se dá, é diaspórica - o que implica em dizer que ela não é simples. Ela faz adoecer, mata, leva décadas para se dar. Esta mulher é constantemente desqualificada, apagada, sobrevive na (apesar da) injustiça. Portanto, as camadas de violências são muitas: física, mental, epistemológica, cognitiva, social. A negativa deste processo no mínimo revela que a necessidade de elaboração de um processo pedagógico para a branquitude é urgente e fundamental. É necessário à branquitude rejeitar a comodidade e a hipocrisia da negação e fazer ela mesma a sua travessia. O letramento racial e um aprendizado antirracista dizem respeito a interrupção por parte de pessoas brancas da repetição das estruturas de opressão, de morte e de produção de privilégios, calcados justamente na negação do racismo e suas violências.

Há muita violência na construção da loucura negra, como signo atribuído e como processo de adoecimento decorrente das investidas sociais. As camadas de "memórias vivas enterradas em nossa psiquê" (KILOMBA, 2019:33), para falar com Grada Kilomba, são extremamente violentas e nos atravessam segundo a segundo, através das histórias de nossas ancestrais reiteradas em nós, em nossa mente e nosso corpo. Novas narrativas nos servem e, como processo educativo, também são necessárias à branquitude, que precisa, e pode, perlaborar sobre "a parte que lhe cabe" no problema colonial. A maturidade da sociedade (e ela é feita de indivíduos) requer o confronto. Se

\footnotetext{
${ }^{3}$ Sugiro a leitura de autores como Lélia Gonzalez, Grada Kilomba, Joel Zito Araújo, Sueli Carneiro, Stuart Hall, entre tantos outros.
} 
o campo da psicanálise é eurocêntrico e demonstra profunda dificuldade em conferir atenção e importância às consequências psicológicas do racismo sobre os corpos negros, ela é um espaço acolhedor para o sujeito branco e burguês. Isto não deve ser só coisa das "nossas" cabeças, deve ser das "suas" também. O racismo mata em diversas instâncias, leva à depressão, à síndrome do pânico, à loucura, ao suicídio. A denegação da latinoamefricanidade, na forma do racismo, se volta para aqueles que são os testemunhos vivos dela, tentando exterminá-los: “O racismo 'à brasileira' se volta justamente contra aqueles que são testemunho vivo da mesma (os negros), ao mesmo tempo que diz não o fazer ('democracia racial' brasileira)" (GONZALEZ, 1988:69).

De antemão, para nós, a enunciação é um direito a ser conquistado - isto já define parte essencial da violência. Primeiro porque a fala, habilidade da condição humana, foi amputada, a fim de endossar a fantasia da inumanidade dos sujeitos racializados a partir do signo da negritude. No que diz respeito ao direito a fala, ele se dá sempre em pretérito imperfeito, onde a dúvida quanto "a outorga" concedida é sempre atualizada: a sujeita negra tem sempre de provar o "x da questão". A depender dos espaços nos quais circula, com mais violência. Existem direitos evidentemente adquiridos no campo das virtualidades coletivas, mas que não se aplicam nas expectativas cotidianas, no território das individualidades, e na relação individualcoletivo (como, por exemplo, nos ambientes de trabalho ou nos círculos acadêmicos). Quando a sujeita fala há sempre (supra) expectativa e deslegitimação, o que é evidentemente um contrassenso (há ainda um certo grau de condescendência doentio, o que também é uma forma de inferiorização - há camadas de complexidades na questão). Para Grada Kilomba, falar se torna potencialmente impossível, pois "quando falamos, nosso discurso é frequentemente interpretado como uma versão dúbia da realidade, não imperativa o suficiente para ser dita nem tampouco ouvida" (KILOMBA, 2019:42). A impossibilidade de uma relação de convívio horizontal explicita o quanto o falar e o não falar fazem parte de um mesmo projeto, no qual se estabelece uma negociação entre quem fala e quem escuta. Se há, portanto, uma recusa a ouvir o falante, se ele não está plenamente autorizado, ele "não pertence”, está extirpado.

Além da fala (ou da ausência dela e suas implicações), evidencia-se o processo de inversão próprio da modernidade como visão de mundo, através do qual fantasia-se que o sujeito negro quer possuir algo que pertence ao branco. Em Memórias da Plantação, Grada Kilomba chama a atenção para o fato de que moralmente "os frutos" 
[do trabalho] pertencem aos colonizados (2019:34-46). Nesse aspecto, a pensadora se refere às plantations, mas eu, por acréscimo, me refiro aos bens e direitos que sustentam nossa sociedade de uma forma geral na contemporaneidade. Na dinâmica da inversão, onde o status de agressor cabe ao agredido e o de agredido ao agressor, está implícita a negação. Considerando que "a plantação" moralmente pertença ao colonizado, a pensadora explica que o colonizador interpreta esse fato perversamente, invertendo a narrativa para que assim a ideia de posse (o sujeito negro como detentor de algo) seja interpretada como roubo. É porque o negro quer obter aquilo que teoricamente é do sujeito branco que ele precisa ser paralisado e qualquer ação contrária está satisfatoriamente justificada.

A "máscara do silêncio" (2019:35) imposta aos negros no período escravocrata como um objeto de tortura é recuperada por Grada Kilomba em sua obra, onde a autora formula uma metáfora para a reflexão de como, enquanto opressão, a máscara, como signo para a compreensão do sistema colonial como um todo, continua a se impor e a exercer o seu poder nos dias de hoje. No contexto de sua intangibilidade, a máscara ganha formas imateriais e materiais, torturando os corpos negros nas mais diversas camadas. É preciso considerar assim que a repressão protege o sujeito branco de ouvir o que o sujeito negro tem a dizer, de reconhecer o conhecimento deste e, evidentemente, de manter o conhecido desconhecido:

\begin{abstract}
O medo branco de ouvir o que poderia ser revelado pelo sujeito negro pode ser articulado com a noção de repressão de Sigmund Freud, uma vez que a 'essência da repressão', segundo o mesmo: "Encontra-se simplesmente em afastar-se de algo e mantê-lo à distância do consciente (Freud, 1923, p. 17). Esse é o processo pelo qual ideias -e verdades - desagradáveis se tornam inconscientes (...). Enquanto enterradas no inconsciente como segredos, permanecem latentes e capazes de ser relevadas a qualquer momento. (...) Uma vez confrontado com verdades desconfortáveis dessa história muito suja, o sujeito branco comumente argumenta "não saber", "não entender", "não se lembrar", "não acreditar" ou "não estar convencido". Essas são expressões desse processo de repressão, no qual o sujeito resiste tornando consciente a informação inconsciente, ou seja, alguém quer fazer e manter o conhecido desconhecido (KILOMBA, 2019:41-42).
\end{abstract}

Na complexa sociedade da manutenção dos privilégios a ideia de bem comum simplesmente não é aceitável. Nesta medida, atrelando à reflexão as demandas urgentes de um pensamento pós-abissal (SANTOS, 2007), para uma cartografia do Sul Global, constituída por novas bases epistemológicas, é preciso compreender as investidas do 
processo reiterado de "apropriação/violência" sobre o exercício da "regulação/emancipação", de que fala o sociólogo Boaventura de Sousa Santos. Neste jogo de teor positivista, a inversão continua sendo uma estratégia ardilosa da colonialidade. A regulação/emancipação não consegue dar conta, por exemplo, dos números que definem a vida negra feminina. No quesito emprego as mulheres negras não continuam recebendo menos que todos os outros indivíduos nas relações de trabalho? Isto no exercício da mesma função e com o mesmo grau de escolaridade. Em 2018, recebemos em média menos da metade dos salários dos homens brancos $(44,4 \%)$. O que significa dizer que continuamos a receber menos que os homens negros, que recebem menos que as mulheres brancas, que recebem menos que os homens brancos. ${ }^{4}$ Mas talvez isso seja apenas “mimimi” e ninguém precise de fato se importar com isso.

O racismo é um fenômeno presente em diversas sociedades contemporâneas, latente na cultura, nas instituições e no cotidiano das relações entre os seres humanos. No entanto, há pessoas que não o enxergam ou preferem não vê-lo. [...] As crenças racistas não recuam, apesar de as pessoas terem mais acesso à ciência através da educação, o que mostra que a racionalidade em si não é suficiente para que todas as pessoas possam abrir mão de suas crenças racistas. Em outros termos, os racistas são movidos por outra racionalidade, que não é necessariamente científica (MUNANGA, 2017:33).

Quando Kabengele Munanga ressalta que ainda que sujeitos racistas mesmo tendo acesso à educação e à ciência continuam a exercer práticas criminosas, ele enfatiza a dimensão do problema: histórica, social, simbólica e também psicológica. Frantz Fanon explica justamente que a irracionalidade do racismo é o trauma. No processo de negação no qual o "senhor" nega seu projeto de colonização e o impõe ao colonizado, o sujeito afirma algo sobre a/o "outra/o" que se recusa a reconhecer em si próprio, o que se caracteriza como o mecanismo "de defesa do ego" (FANON, 2008:34). O opressor se nega a admitir seu processo de opressão (de apropriação) sobre o "outro" para que este "outro" se torne o "inimigo" a ser combatido. O "intruso" (o sujeito negro) torna-se o tirano (o opressor) e o branco torna-se a vítima exorável. Esse fato é baseado em processos nos quais partes cindidas da psiquê são projetadas para fora, criando o chamado "Outro", sempre como antagonista do eu (self).

\footnotetext{
${ }^{4}$ Os dados fazem parte da pesquisa Desigualdades Sociais por Cor ou Raça, publicada pelo Instituto Brasileiro de Geografia e Estatística (IBGE), em 2019.
} 
Nesse contexto que fomenta nossa psicologia (psicopatia) social a branquitude é vista, internalizada, como a parte boa do ser e a negritude como a parte má. Aspectos como agressividade e sexualidade são atribuídos ao negro e isto já não é uma novidade. Para Grada Kilomba, a supracitada cisão sustenta o fato de que o sujeito branco está dividido dentro de si, desenvolvendo atitudes distintas em relação a realidade externa: a parte boa (acolhedora e benevolente) corresponde a parte do seu "ego" vista como "o eu"; a parte ruim/má (malévola e rejeitada) é projetada sobre "o outro" (o negro). Neste ponto é que o sujeito negro se torna a "tela de projeção daquilo que o sujeito branco teme reconhecer sobre si mesmo" (KILOMBA, 2019:37). A verdadeira alienação negra se constitui do pensamento que se constrói sob a ótica do outro: este é um dos pilares da loucura anunciada. De fato, uma grande dor mora na não conexão com a sociedade pensada a partir de dogmas eurocêntricos, estruturada na falta de identificação com a realidade externa tal qual ela se apresenta, rejeitada pela impossibilidade de se encaixar nas fantasias violentas sobredeterminadas sobre o sujeito negro.

Poderíamos dizer que no mundo conceitual branco é como se o inconsciente coletivo das pessoas negras fosse pré-programado para a alienação, decepção e trauma psíquico, uma vez que as imagens da negritude às quais somos confrontadas/os não são nada realistas, tampouco gratificantes. Que alienação, ser-se forçada/o a identificarse com os heróis, que aparecem como brancos, e rejeitar os inimigos, que aparecem como negros. Que decepção, ser-se forçada/o a olhar para nós mesmas/os como se estivéssemos no lugar delas/es. Que dor, estar presa/o nessa ordem colonial (KILOMBA, 2019:39).

O fato de que a branquitude é construída a partir da outridade leva mulheres negras a precisarem lidar com fantasias construídas por sujeitos brancos (ou lidos como) e esta condição das existências femininas negras reatualizam o trauma cotidianamente, e podem tanto fragilizar as vítimas quanto confundir o discurso e as narrativas que se esforçam em elaborar. Tanto porque há um enorme esforço para escapar das demarcações que nos são impostas, e neste esforço não há espaço nem tempo para a fragilidade, ou para o erro, ou para a reflexão do processo da dor que advêm desta gama de processos traumáticos. Este "tempo" é uma prerrogativa branca.

Também porque quando começamos a parecer escapar de certa demarcação colonial há uma enorme investida a fim de promover o aniquilamento desta possibilidade, o impedimento. Neste processo no qual somos excretadas da sociedade há uma patrulha de silenciamento constante e de morte, que reencena o exercício do 
apagamento como estratégia inicial. Nesta cena da sociedade dos méritos, os "capitães do mato" contemporâneos recebem seus louros, e os negros "não-adaptáveis", os rebeldes, os não assimilados, não podem sequer comer da migalha que cai da mesa dos seus "senhores". 5 O que dizer então das mulheres negras, estas que são as mais marginais das criaturas? É preciso entender que ser estimulada a sempre pensar a partir da presença alienante do outro não é simples.

A insanidade para nós, mulheres negras, é tanto uma fantasia projetada (das fantasias sobredeterminadas), na qual esperam que nos enquadremos, quanto um fantasma do qual temos de nos desviar com esforço. Há uma grande investida sobre a sanidade da mulher negra, nas instâncias da vida pública e privada - na sobreposição de ambas, na negação de ambas. Um corpo feminino negro (ainda) é lido como último pilar na escala social (e isto também não é mais uma novidade); ainda é interpretado como objeto de uso, sexualizado, folclorizado, tido como desimportante, atrelado à servidão como um destino. Basta observar a forma como o racismo se manifesta nas redes sociais para entender a atualidade pretérita da questão. Não me parece que os estigmas tenham sido superados.

Somos sim enlouquecidas pelo racismo nos espaços de trabalho, nas universidades, nas instituições públicas, no sistema de saúde, na sobrecarga de afazeres. Somos enlouquecidas pelo medo do extermínio, pelo genocídio. Pelo medo do estupro. Somos enlouquecidas pela violência cognitiva e pelo epistemicídio ${ }^{6}$. Enlouquecemos porque quanto a nós precisamos ser sempre "fortes" (nunca frágeis, nunca feridas). Porque somos xingadas, preteridas, roubadas e não há discurso antirracista de capa de revista, feminismos de Instragram e podcasts ou explicações psicanalíticas (ou não) que se importem em conferir respostas a isto como uma práxis não maniqueísta. Enlouquecemos pela solidão destas demandas.

Somos enlouquecidas porque somos estimuladas ao auto-ódio ainda quando nem mesmo sabemos o que é ódio. Porque precisamos explicar vezes incessantes que as coisas funcionam de forma bem diferente para nós e isto não é um ponto de vista.

\footnotetext{
${ }^{5}$ Parafraseando o trecho de Mateus 15:27, da Bíblia Cristã: "E ela disse: Sim, Senhor, mas também os cachorrinhos comem das migalhas que caem da mesa dos seus senhores. Então respondeu Jesus, e disselhe: Ó mulher, grande é a tua fé! Seja isso feito para contigo como tu desejas. E desde aquela hora a sua filha ficou sã."

${ }^{6}$ Processo em que se dá a morte simbólica, o apagamento de referenciais africanos e afro-brasileiros, e que se atrela ao genocídio do corpo negro. O termo utilizado por Boaventura de Sousa Santos tem sido utilizado para se referir a influência da cultura europeia (branca) e do imperialismo capitalista sobre os processos de produção, reprodução da vida e da morte.
} 
Porque temos de falar sobre racismo todos os dias. Porque ganhamos menos e precisamos trabalhar mais. Vamos caminhando para os manicômios públicos nos mesmos passos de nossos antepassados porque a escritora Conceição Evaristo chega "ao sucesso" apenas agora, tendo décadas inteiras de contribuições para a literatura e a Academia. Porque Elza Soares, a cantora, ganhou agora status de Rainha. Esperam que estas mulheres agradeçam. Enlouquecemos porque não há gratidão. Quando não enlouquecemos é porque a partir da inumanidade imposta há um esforço sobre-humano de transmutação da dor - e, por isso, também acabamos por enlouquecer.

Racismo? No Brasil? Quem foi que disse? Isso é coisa de americano. Aqui não tem diferença porque todo mundo é brasileiro acima de tudo, graças a Deus. Preto aqui é bem tratado, tem o mesmo direito que a gente tem. Tanto é que, quando se esforça, ele sobe na vida como qualquer um. Conheço um que é médico; educadíssimo, culto, elegante e com umas feições tão finas... Nem parece preto (GONZALEZ, 1984:226).

Para Lélia Gonzalez (1984), o racismo se constitui como uma sintomática que caracteriza a neurose cultural da sociedade brasileira (produto da apropriação/violência, da negação, do mito da democracia racial, dos processos eugênicos e de um processo delicado de regulação/emancipação), onde se nega inclusive as indiscutíveis contribuições negras para o processo de formação de nossa cultura. A intelectual, já na década de 1980 avisava que "o lixo ia falar, e numa boa", provocando um ruído de entendimento, subvertendo o sentido da narrativa e incitando uma reflexão capaz de escapar ao determinismo dos dogmas eurocêntricos. Ela se valeu das noções de consciência e de memória para promover uma reflexão mais ampla acerca de nossa formação social em paralelo com o racismo.

A consciência é entendida por Lélia Gonzalez como o lugar do desconhecimento. A consciência diz respeito ao encobrimento, a alienação, ao esquecimento, e também ao saber. O discurso ideológico se faz presente justamente no âmbito da consciência, já a memória, é considerada como o não-saber que conhece, esse lugar de inscrições que restituem uma história não escrita, "o lugar da emergência da verdade, dessa verdade que se estrutura como ficção. A consciência exclui o que memória inclui" (GONZALEZ, 1984:226). A consciência, como lugar da rejeição, se expressa como discurso dominante, ocultando a memória mediante a imposição do que ela, a consciência, afirma como a verdade. 
Mas a memória tem suas astúcias, seu jogo de cintura: por isso, ela fala através das mancadas do discurso da consciência. O que a gente vai tentar é sacar esse jogo aí, das duas, também chamado de dialética. $\mathrm{E}$, no que se refere à gente, à crioulada, a gente saca que a consciência faz tudo prá nossa história ser esquecida, tirada de cena. E apela prá tudo nesse sentido. Só que isso ta aí... e fala (GONZALEZ, 1984:226227).

Em muitos de seus textos Lélia Gonzalez provoca uma espécie de palavra plástica $^{7}$, onde as palavras ganham corpo e cor, suscitam novas imagens na elaboração de uma episteme que descortina princípios e práticas hegemônicas. O pensamento pósabissal (SANTOS, 2007:76) entende que a cartografia metafórica das linhas globais sobreviveu à cartografia literal das linhas que separavam o Velho Mundo do Novo Mundo e formula que a injustiça social global está intimamente ligada à injustiça cognitiva global, de forma que a luta pela justiça social passa pela luta pela justiça cognitiva global. $\mathrm{O}$ esforço de descentramento implica em desfamiliarizar o conhecimento canônico como o único possível. Nesse sentido é dar a ver muito do que antes estava oculto em nossas estruturas mentais e no pensamento social; é deter-se, e também provocar, outra episteme na confrontação dos processos hierárquicos atrelados aos saberes; é referenciar-se em outras visões de mundo em que o processo de organização do pensamento não passe pela produção de inexistências. A produção de novas narrativas e novas imagens é essencial ao pensamento feminino negro porque, antes de tudo, é uma questão de saúde - ela que deveria ser um direito de todo cidadão desde 1888, ou melhor, desde sempre.

Sueli Carneiro pontua que a conjugação do racismo com o sexismo produz sobre as mulheres negras uma espécie de "asfixia social" (CARNEIRO, 2011:127) com desdobramentos negativos que se manifestam em sequelas emocionais com danos à saúde mental; rebaixamento da autoestima; expectativa de vida menor em relação às mulheres brancas; menor índice de casamentos; e no confinamento em ocupações profissionais de menor prestígio e remuneração. No artigo Aquelas negas, a filósofa recupera um episódio que nos ajuda a compreender o motivo pelo qual transmutar as ideias limitadoras impostas a nós é uma forma de elaborar uma existência possível diante das sutilezas do racismo (há violência nas sutilezas): a jogadora Virna Dias, no

7 Termo que utilizo em pesquisa de doutoramento na Pós-Graduação Literatura, Cultura $e$ Contemporaneidade, da PUC-Rio, sob orientação do professor Alexandre Montaury. 
"auge da euforia", depois de derrotar a seleção de vôlei da Alemanha, disse o seguinte diante das câmeras de televisão: "Agora vamos pegar as cubanas, aquelas negas, e vamos ganhar delas!" (2011:124). Refletindo sobre esta "necessidade de adjetivar racialmente" as jogadoras cubanas, Sueli Carneiro questiona o que mais teria incomodado Virna Dias (ela usa o termo "ressentimento") nesta disputa histórica: perder para uma seleção mais forte, perder para "aquelas negas", ou, ainda para as negas que são mais fortes.

Para alguns brancos (e outros que assim se supõem), parece só haver um jeito suportável de ser negro: aquele ligado ao fracasso, à vulnerabilidade, ao servilismo, à dependência e à inferioridade introjetada. Negros e negras fortes, altivos e vencedores parece um insulto para esses brancos. (...) Mas não há nada de novo no front. É só mais um ato falho que vemos ou sofremos todo o tempo nessa sociedade. Em todos os conflitos ou disputas entre brancos e negros os adjetivos "criolo", "nega safada", "macaco" etc. são usados para expressar o desprezo pela negritude e assim valorizar o oponente branco. A brancura funciona como um elemento que sempre desempataria em favor do branco. (...) Em geral, esses atos são minimizados pela opinião pública como uma frase infeliz, sem intenção discriminatória, de acordo com a nossa tradição de mascarar o racismo e o preconceito presentes em nossa sociedade (CARNEIRO, 2011:124-125).

Como forma de elaborar o trauma muitas mulheres negras têm realizado através da experiência estética e intelectual uma transmutação dos signos da dor. Um processo de cura ou, pelo menos, de uma melhor existência através da consciência. bell hooks (2019) diz que amar a negritude como resistência política transforma nossas formas de ser e ver, criando condições necessárias para que nos movamos contra as forças de dominação e morte que tomam as vidas negras, através dos processos reiterados do "passado" e à medida que a democracia agoniza. Seja através do exercício do pensar a partir de novas bases epistemológicas (como realizado por Sueli Carneiro, Grada Kilomba, bell hooks, Lélia Gonzalez e inúmeras outras importantes pensadoras e pensadores negros), da produção de novas bases bibliográficas ou da realização artística - território onde muitos pensadores negros tem atravessado e transmutado o racismo, além de propor novas cosmogonias do pensamento -, a produção de novas imagens mentais, novos signos e novas narrativas se torna fundamental. 
No campo das artes as performances afro-atlânticas ${ }^{8}$ incluem o que a arte eurocêntrica exclui. Se observarmos, por exemplo, as exposições de Rosana Paulino, o teatro de Fernanda Júlia, de Hilton Cobra, a literatura de Conceição Evaristo, de Eliana Alves Cruz, ou o cinema de Adélia Sampaio, entenderemos que é benéfico ressignificar, em perlaboração, a experiência da travessia do Atlântico. A professora e pesquisadora Daiana Nascimento dos Santos chama a atenção para a importância das ressignificações na perspectiva das reparações:

No quadro da história moderna, o oceano Atlântico foi configurado como um espaço multifacetado de conexões econômicas, sociais e políticas; também de reelaborações estruturais da escravidão e confabulações culturais preocupadas com a reivindicação da história negra e da memória traumática (SANTOS, 2015:29). ${ }^{9}$

Todo o processo colonial de apagamento, de promoção da baixa autoestima, promoção da loucura e do silenciamento é a causa primeira da incessante busca por imagens que suscitem representatividade, visibilidade, empregabilidade e produção de novos discursos. A perspectiva de uma correção cognitiva produz novos marcos epistemológicos, de potencial imprescindível não apenas para uma epistemologia pósabissal, mas, como estímulo intelectual a branquitude, afinal, há urgência de que esta parcela da sociedade "resolva" a sua parte em relação ao racismo. Há urgência de que percorram algumas das léguas epistemológicas que já percorremos, e isto sem que precisemos sempre tomá-la pelas mãos como crianças inocentes e sem juízo.

A própria experiência de visitar memórias, angústias e traumas encontra um espaço não apenas de avaliar nossa condição de "comunidade", de conexões atlânticas e diaspóricas, no sentido de Paul Gilroy (2012), mas também de visitar, pela inquietação, os fantasmas que assombram nossas próprias subjetividades. Trata-se de uma memória viva, ou memórias, do passado e do hoje, enterradas na psique e somatizadas em nosso corpo. De uma forma esquizofrênica, a experiência deste diálogo com o intátil acaba por visitar lugares de tensão que esbarram no senso de mudez e medo, operado primeiro

\footnotetext{
${ }^{8}$ Conceito que desenvolvo em pesquisa de doutoramento na Pós-Graduação Literatura, Cultura $e$ Contemporaneidade, da PUC-Rio, sob orientação do professor Alexandre Montaury.

${ }^{9}$ Versão original: "Enel marco de la historia moderna, el océano Atlántico se ha configurado como un espacio multifacético de conexiones económicas, sociales y políticas; también de reelaboraciones estructurales de la esclavitud y de confabulaciones culturales preocupadas por la reivindicación de la historia negra y de la memoria traumática”.
} 
pelo terror da tal máscara de silenciamento colonial. Refazer é ainda o espaço aberto para uma reparação histórica. Neste sentido, há que se visitar outros lugares em nós: estes onde o silêncio pode ser, além da agonia de uma condição imposta, uma estratégia de sobrevivência e/ou a habitação tornada comum. O contrário disto não é apenas falar, mas produzir. Produzimos para não enlouquecer. Produzimos para uma real democracia, para que esta não continue a ser neste presente pretérito contínuo a própria utopia.

Deixem-nos produzir! Viveremos.

\section{Referências}

ALVES, Renata Carmo; COUTINHO, Alexandre Montaury Baptista (Orientador). As faces de Maria: ecos de Maria Firmina dos Reis em Lélia Gonzalez, Djamila Ribeiro e Marielle Franco. 2019. Dissertação de Mestrado (em Letras) - Pontifícia Universidade Católica do Rio de Janeiro, Rio de Janeiro, 2019.

CARNEIRO, Sueli. O matriarcado da miséria. In: CARNEIRO, S.. Racismo, sexismo e desigualdade no Brasil. São Paulo: Selo Negro, 2011.

'Aquelas negas'. In: CARNEIRO, S.. Racismo, sexismo e desigualdade

no Brasil. São Paulo: Selo Negro, 2011.

FANON, Frantz. Pele negra, máscaras brancas. Salvador: EDUFBA, 2008.

GILROY, Paul. O Atlântico negro: modernidade e dupla consciência. São Paulo: Editora 34, 2012.

GONZALEZ, Lélia. A categoria político-cultural de amefricanidade. Tempo Brasileiro. Rio de janeiro, 92/93, 1988. Disponível em: https://negrasoulblog.files.wordpress.com

Racismo e sexismo na cultura brasileira. Revista Ciências Sociais Hoje,

Anpocs, $1984 . \quad$ Disponível em: https://edisciplinas.usp.br/pluginfile.php/247561/mod_resource/content/1/RACISMO\% 20E\%20SEXISMO\%20NA\%20CULTURA\%20BRASILEIRA.pdf

HOOKS, bell. Olhares negros: raça e representação. São Paulo: Elefante, 2019.

KILOMBA, Grada. Memórias da plantação - Episódios de racismo cotidiano. Rio de Janeiro: Cobogó, 2019.

MUNANGA, Kabengele. As ambiguidades do racismo à brasileira. In: $O$ racismo e o negro no Brasil - Questões para psicanálise. São Paulo: Perspectiva, 2017.

SANTOS, Boaventura de Sousa. Para além do pensamento abissal. Das linhas globais a uma ecologia dos saberes. Novos estudos 79. São Paulo, 2007. Disponível em: http://www.scielo.br/pdf/nec/n79/04.pdf 
SANTOS ${ }^{2}$, Daiana Nascimento dos. El océano de fronteras invisibles: relecturas históricas sobre (el fin? de) la esclavitud en la novela contemporánea. Madrid: Editorial Verbum, 2015.

\title{
NEW IMAGES FOR NON-CRAZY BLACK WOMEN
}

\begin{abstract}
The essay proposes to think about the symbolic (and psychic) fissures of racism as a discursive practice of modern thought. The (production of) madness, therefore, is a sign of imposed delegitimation and a strategic scheme for the annihilation of the black woman's body and the promotion of exclusion. Thus, the construction of new epistemological bases for social understanding is as much part of the current democratic struggles as a public health issue.
\end{abstract}

\section{Keywords}

Black woman. Trauma. Madness. New narratives. 